\title{
O DESAFIO DA ALFABETIZAÇÃO: O MÉTODO E SUAS IMPLICAÇÕES TEÓRICO- TÉCNICAS.
}

\author{
Andréa Henrique Franco Bertan ${ }^{1}$; Lucia Helena Tiosso Moretti ${ }^{2}$ \\ ${ }^{1}$ Mestre em Educação pela UNOESTE. ${ }^{2}$ Docente do Programa de Mestrado em Educação da UNOESTE
}

\begin{abstract}
RESUMO
Este trabalho teve por objetivo analisar a alfabetização juntamente com os Projetos Políticos Pedagógicos de duas escolas de uma cidade da região norte do Paraná. Preocupou-se em investigar os problemas que envolvem a alfabetização: suas teorias, metodologias e aplicabilidade do PPP. A metodologia empregada neste estudo foi o Estudo de Caso, analisando as teorias de ensino, a observação participante em sala de aula, entrevistas com professores e análise dos resultados. A pesquisa envolveu duas instituições, uma pública e outra particular, de forma a se fazer um comparativo entre as metodologias e teorias aplicadas na prática da alfabetização e a análise do PPP de cada escola. A amostra foi composta por quatro professoras da escola municipal e uma professora da escola particular, todas atuando na $1^{\mathrm{a}}$ série do ensino fundamental. As entrevistas foram realizadas individualmente para que as professoras falassem à vontade, sem interrupções. As observações em sala de aula foram feitas duas vezes por semana, nas quais, ass metodologias aplicadas nas aulas e as relações com o PPP das escolas foram objeto de análise. As observações registradas revelaram as coerências e incoerências da prática de ensino da alfabetização, o quanto estas práticas estão ou não alinhadas à proposta pedagógica do PPP de cada escola.
\end{abstract}

Palavras - chave: método de alfabetização, formação docente, projeto político pedagógico, metodologia, teorias de ensino, observação participante

\begin{abstract}
The objective of this paper was to analyze the literacy along the Pedagogical Political Projects (PPP) of two schools of a city of north Parana State. The focus was on investigating the problems that involve the literacy process: theories, methodologies and the applications of the PPP. The methodology used to develop this study was through Case Study. It involved a public and a private school, so that could be compared the methodologies and the theories applied in the literacy practice and the analysis of PPP from each school. The sample was compounded by four teachers from the public school and one from the private one, all of them teaching in the first grade of Fundamental level. The interviews were individual so the teachers could feel free to answer without any interruptions. The observations were made twice a week through the analysis of the methodologies used in class and the relation with the PPP of each school. They revealed the coherences and incoherences of the work in literacy teaching, and how much these practices are or not lined with the pedagogical propose of the PPP from each school.
\end{abstract}

Key-words: literacy process, teachers formation, pedagogical political project, methodology, teachings'theory, participate observation 
Introdução

Atuando como docente, as questões do processo de ensinoaprendizagem, como conteúdos, metodologias, procedimentos de ensino e avaliação, nos despertam o desejo de aprimorar nossa formação didáticopedagógica para melhor compreender a complexidade do ato de ensinar e aprender. Por isso, desenvolver um trabalho que envolve a prática de ensino em sala de aula, com a teoria proposta pelos métodos de ensino e adotados pela escola, foi um grande desafio e motivo para - crescimento da nossa formação profissional como educadora.

Um grande desafio da educação hoje é o de exercer o seu papel de instrumento de promoção humana numa sociedade de exclusão, onde um grande número de pessoas é simplesmente considerado dispensável. $\mathrm{O}$ acesso ao conhecimento, à verdade, ao bem, à valorização da pessoa humana, pode determinar significativamente a manutenção ou a transformação desta realidade.

A alfabetização nas séries iniciais é um tema de discussão constante, muito recorrente em trabalhos de pesquisa na área da educação, dada a suma importância que este tema abrange e também devido aos inúmeros métodos de ensino que são aplicados em sala de aula.

Fatores culturais contribuem decisivamente na educação. Morais (1992, p. 8), afirma que "o conceito de cultura é o resultado das ações do homem com o mundo e com os seus semelhantes".
A educação não pode ignorar as fortes mudanças culturais da atualidade. Quando prevalece muito uma cultura universal, sem espaço definido, uma cultura de massa, cria-se, aos poucos, uma cultura da superficialidade e do efêmero, e essa cultura do cotidiano também se estabelece na prática pedagógica. Surgem os modismos e estes acabam de uma forma ou de outra influenciando nos discursos e nas práticas pedagógicas em sala de aula.

A situação se agrava, conforme aponta Severino (2000), quando o ensino brasileiro se restringe mais à reprodução dos conteúdos do que à construção do conhecimento.

\section{Referencial Teórico}

A fundamentação teórica desta pesquisa envolveu temas importantes da educação. $O$ primeiro objeto de fundamentação teórica foi sobre a alfabetização, seu significado e os fatores que envolvem a alfabetização. Também foi necessário aprofundar-se no significado do Projeto Político Pedagógico (PPP) de cada escola, seu papel no direcionamento dos professores em sala de aula e sua função na estrutura da escola. Os métodos de ensino, as principais escolas teóricas e seus fundamentos, principalmente as correntes de ensino citadas pelos PPPs das escolas e por seus professores, também foram objetos de fundamentação teórica para esse trabalho.

A alfabetização é um dos temas mais discutidos na área da educação. Há diversos conceitos sobre a alfabetização, o mais simples define a alfabetização como o 
processo pelo qual um indivíduo constrói a habilidade da leitura e escrita de uma determinada língua.

Moll (1996, p. 68) destaca a definição do conteúdo etimológico do processo de alfabetização. Nesta definição a alfabetização se reduz a uma esfera mecânica, na qual "alfabetizar-se" está vinculado a habilidades de codificação (representação escrita de fonemas em grafemas) e de decodificação (representação oral de grafemas em fonemas).

Para Soares (apud Carvalho, 2005, p. 9) alfabetizar é ensinar crianças e adultos a ler, a conhecer os sons que as letras representam e, ao mesmo tempo, com a mesma ênfase, convidá-los a se tornarem leitores, a participarem da aventura do conhecimento implícita no ato de ler. A autora coloca que uma pessoa alfabetizada conhece o código alfabético, domina as relações grafofônicas, ou seja, sabe os sons que as letras representam, é capaz de ler palavras e textos.

Carvalho (2005, p. 65) coloca que alfabetização é a ação de ensinar (ou o resultado de aprender) o código alfabético, ou seja, as relações entre letras e sons. Carvalho também comenta que existem definições mais amplas de alfabetização que incluem as habilidades de interpretação de leitura e produção de escrita, e até de conhecimento do mundo, mas, destaca o caráter específico da alfabetização, considerando um processo limitado no tempo, no conteúdo e nos objetivos.
Para Freire, a alfabetização não é entendida como uma memorização de babe-bi-bo-bu e nem como uma transferência de conhecimento da escrita do alfabetizador para o alfabetizando. A alfabetização é um processo de busca e tentativas de revolução, portanto, nunca uma recepção passiva, como 0 ato de conhecimento que tem como objeto a ser conhecido a língua escrita. (BARRETO,2004, p. 81),

A metodologia didática refere-se ao conjunto de métodos e técnicas de ensino para a aprendizagem. O método é então o caminho com que o professor, de modo direto e significativo, conduz o aluno à aprendizagem. São vários os métodos e técnicas de ensino em sala de aula que as escolas e professores adotam para realizar o processo de alfabetização de seus alunos. Inclusive, algumas escolas e professores não se fixam apenas a uma ou outra teoria de ensino, partindo também para uma mistura de teorias e métodos de ensino, criando assim um ecletismo para alfabetização dos alunos.

Para Filho (apud Bertan, 1994, p. 54), do ponto de vista didático, na pedagogia tradicional "o trabalho dos alunos se caracterizava por uma atitude de receptividade ou absoluta passividade".

A Escola Tradicional traz uma proposta de educação centrada na figura do professor. O princípio é a transmissão de conhecimentos por meio da aula, freqüentemente expositiva, numa seqüência predeterminada e fixa que enfatiza a repetição de exercícios com exigência de memorização. Muitas vezes 
não leva em conta o que a criança aprende fora da escola

Quanto às teorias norteadoras do processo ensino - aprendizagem, o Construtivismo constitui-se numa posição epistemológica que se refere a como se processa o conhecimento, estabelecendo que $O$ sujeito é quem constrói o conhecimento. Sua tarefa é explicar como ocorre o conhecimento no interior do sujeito. Para o construtivismo, a produção do conhecimento compreende uma posição interacionista em que o conhecimento é o resultado da ação do sujeito sobre a realidade.

O Construtivismo enfatiza o conhecimento que a criança já tem antes de ingressar na escola e está focado na língua escrita. Existem distorções na aplicação do conceito, sendo que uma delas é a de que não se deve corrigir os erros dos alunos. O Construtivismo é a linha atualmente seguida pelas escolas públicas brasileiras, aconselhadas pelos Parâmetros Curriculares Nacionais (PCNs).

As bases do construtivismo estão pautadas nas teorias de Piaget (18961980) e Vygotsky (1896-1934). Segundo Becker (1996), o construtivismo é uma teoria que "nos permite interpretar o mundo em que vivemos", e que, para Piaget, é o mundo do conhecimento: sua gênese e seu desenvolvimento, pois aprendizagem só tem sentido na medida em que coincide com o processo de desenvolvimento do conhecimento, com o movimento das estruturas da consciência.

Para Vygotsky, o papel social da escola se refere à relação indivíduo e sociedade. As características tipicamente humanas resultam da interação do homem e seu meio sócio-cultural. As funções psicológicas se originam das relações do indivíduo e seu contexto cultural e social. $O$ sujeito é moldado pelo social. O cérebro é visto como órgão principal da atividade mental.

Piaget define a criança como um ser ativo que age espontaneamente sobre o meio, de modo a organizar suas experiências. A criança vai construindo seu conhecimento através do contato com as pessoas e com os objetos. (REGO, 1995)

Arce (2000, p. 41) afirma que o construtivismo no Brasil vem sendo considerado por boa parte dos educadores um grande avanço como concepção sobre o processo educativo. Segundo a autora, o construtivismo deveria ser empregado na própria formação de professores. Arce ainda esclarece que para que alguém se torne um bom professor construtivista, seria necessário que sua formação também ocorresse através de um processo construtivista. Isso permitiria aos professores desenvolverem uma prática profissional coerente com os pressupostos dessa corrente.

O GEEMPA foi fundado em 1970 como um grupo de estudo para o ensino de matemática. Até 1983, o GEEMPA funcionou realizando atividades de formação pessoal, de pesquisa e de divulgação do ensino da Matemática, sob a influência dos estudos piagetianos. Em 1983, o GEEMPA adquiriu uma nova identidade, cujo foco é o estudo, a pesquisa e a ação para o desenvolvimento 
das ciências da educação, junto ao seu compromisso com a educação popular.

Rocha (2003) apresenta de forma sucinta as bases conceituais da proposta geempeniana.

Em termos teórico-conceituais, a proposta geempiana de alfabetização está situada na confluência das obras de Jean Piaget, Henri Wallon, L. S. Vygotski, Sara Pain, Emilia Ferreiro e Paulo Freire, entre outros, lidos a partir da sala de aula, do lugar do professor e de seu compromisso com a efetiva aprendizagem de seus alunos.

Em relação ao Projeto Político Pedagógico, o tema vem obtendo cada vez mais espaço nos últimos anos nos eventos educativos e nas publicações. A Lei de Diretrizes e Bases (LDB, 9.394/96), segundo Lima (2004, p. 187), dá a incumbência às escolas da elaboração participativa de sua proposta pedagógica. Tal incumbência se reverteu, para algumas instituições, em uma obrigatoriedade legal, tornando-se apenas um ato burocrático, 0 que limita a verdadeira função da elaboração do PPP da escola.

O PPP é o documento mestre da instituição de ensino, consiste na formulação de uma proposta educacional, com bases conceituais e políticas que estabelecem a direção em que a instituição de ensino deve se orientar. Este traz uma visão de educação pautada em uma visão de sociedade e que, a partir de seus sujeitos e realidade, traçam uma proposta de ação pedagógica e social. É, portanto, um documento de identidade, no qual os agentes de ensino se vêem e atuam.
Apresentadas as bases teóricas desse estudo, os objetivos desse trabalho foram: explicitar as coerências e as incoerências metodológicas no processo de alfabetização em sala de aula, conhecer o PPP de cada escola analisada e confrontar os conteúdos ministrados em sala de aula com os propostos no PPP de cada escola.

\section{Procedimentos Metodológicos}

O percurso desta pesquisa foi construído por uma metodologia de estudo de caso, delineada em direção ao estudo qualitativo. Participaram do estudo 4 professoras da escola municipal, na faixa etária entre 30 e 55 anos, e uma professora da escola particular, na faixa de 30 anos de idade.

A pesquisa foi desenvolvida em duas escolas, uma municipal e uma particular da cidade de Londrina (PR).

As professoras foram convidadas a participar da pesquisa concedendo entrevistas sobre alfabetização e, algumas delas, cedendo as salas de aulas para que fossem realizadas as observações participantes nas aulas da primeira série do ensino fundamental.

A escola particular está localizada no centro da cidade e a escola municipal está localizada num bairro de periferia distante $10 \mathrm{~km}$ do centro da cidade.

O trabalho de observação ocorreu em duas salas de aula, uma de cada escola, durante as aulas ministradas pelas professoras responsáveis pelas salas da primeira série do ensino fundamental.

Um dos primeiros passos para a realização dessa pesquisa foi o contato com as direções das escolas, no qual foi 
devidamente explicados o tema da pesquisa, os objetivos e as atividades a serem realizadas, bem como solicitar autorização para o desenvolvimento da pesquisa nas escolas.

Quando solicitado o estudo do Projeto Político Pedagógico de cada uma das escolas, a diretora da escola municipal autorizou o empréstimo do do mesmo da escola sem nenhum problema, enquanto que a diretora da escola particular autorizou o estudo do PPP somente na biblioteca da instituição.

Em todos os contatos com as professoras foi deixado bem explícito que as entrevistas seriam gravadas e que 0 nome de nenhuma delas seria divulgado. As entrevistas tinham a finalidade de aprofundar as questões e esclarecer as questões observadas.

As observações realizadas em sala de aula, em cada uma das escolas analisadas tiveram o objetivo de investigar as metodologias utilizadas pelos professores para a realização da alfabetização. Estas, ocorreram durante os meses de março a julho de 2005, nos meses de outubro e novembro, com o objetivo de avaliar o nível de alfabetização das crianças de cada uma das escolas.

Aplicamos uma atividade para verificar em que nível de escrita as crianças se encontravam em dois momentos distintos do ano letivo a Festa Junina. A segunda atividade foi realizada no mês de dezembro e teve como tema A Minha Escola.

Os dados coletados foram submetidos à análise qualitativa conforme os postulados teóricos apresentados no estudo.

\section{Resultados e Discussão}

A pesquisa realizada nas duas escolas envolveu o estudo dos Projetos Políticos Pedagógicos de cada uma, a observação participante dentro da sala de aula, entrevistas com as professoras e a verificação do desempenho dos alunos durante o ano letivo observado.

A pesquisa baseou-se em documentos oficiais das instituições como Regimentos e os Projetos Políticos Pedagógicos. Esses documentos sugerem os objetivos, as diretrizes filosóficas, pedagógicas, políticas, técnicas, científicas e sociais das instituições. Nogaro diz que:

Falar em Projeto Político-
Pedagógico é nos
questionarmos se temos ou
não referencial teórico. O que
nós sabemos sobre educação?
O que é educação para nós? O
Projeto Político-Pedagógico
conterá as grandes linhas de
ação, as idéias que serão
postas em prática. (NOGARO,
1996, p. 69)

A prática em sala de aula deve ser reflexo dos valores contidos no Projeto Político Pedagógico. Mesmo apresentando dois contextos diferentes, foi possível verificar, em cada uma das escolas, a aplicação, em sala de aula, da metodologia de ensino que cada escola diz adotar através do seu Projeto Político Pedagógico.

O Projeto Político Pedagógico da escola particular (2001), está bem completo 
e organizado. Os princípios didáticos e pedagógicos estão bem descritos e fundamentados, assim como a filosofia que a escola adota. A metodologia da escola particular está bem posicionada, definida e descrita segundo fundamentos filosóficos e epistemológicos.

O Projeto Político Pedagógico da escola municipal (2002), não apresenta uma concepção de documento adequada, pois há falhas relacionadas à sua estruturação. A metodologia de ensino está baseada na teoria construtivista de Piaget e de Vygotsky. Apesar da definição explícita e direta do método empregado, há uma carência de aprofundamento epistemológico na descrição do projeto. Há uma descrição bem clara do contexto social em que a escola está inserida, bem como a exposição dos meios de interação entre pais e escola e formas de atitudes entre professores e alunos.

As observações realizadas em sala de aula em cada uma das instituições tiveram por objetivo investigar as metodologias utilizadas pelos professores para a realização da alfabetização no dia a dia da escola. Como estratégia, foram utilizadas técnicas de observação presencial, com registros das atividades realizadas pelos professores em cada uma das salas observadas.

Foram muitos os momentos observados em sala de aula, registrados e vividos no cotidiano das crianças $\mathrm{e}$ professores das duas escolas selecionadas para este trabalho. Com relação à tarefa de alfabetizar em sala de aula, foram observadas grandes diferenças de postura pedagógica, recursos utilizados e utilização de materiais escolares em geral.

Os alunos da $1^{\circ}$ série da escola municipal são crianças carentes no sentido afetivo, econômico e cultural. São de famílias, em geral, disfuncionais, onde há casos de crianças que moram somente com a mãe, pois o pai abandonou a família. Outras vão à escola para comer, visto que a alimentação em casa não é suficiente. Ou, ainda, existem crianças que freqüentam a escola somente para receber - auxílio bolsa-escola, que o governo oferece com a condição de que essas crianças sejam assíduas. O dia a dia dos alunos em sala de aula é bastante diferenciado, em conseqüência desses desajustes citados anteriormente. 
A instituição situa-se num bairro pobre na zona sul da cidade, onde o nível econômico das famílias é muito baixo, o qual acarreta diferentes dificuldades. A sala de aula é relativamente numerosa e bastante heterogênea. As crianças se encontravam no primeiro semestre do ano letivo em diferentes níveis de alfabetização. $\mathrm{Na}$ sala de aula havia alunos que conheciam o alfabeto e outras não. Algumas crianças sabiam escrever o nome, outras sentiam dificuldade de reconhecer as letras. Entretanto, uma pequena minoria de educandos já estava juntando sílabas e escrevendo pequenas palavras.

No início do ano letivo, havia uma indisciplina acentuada em sala de aula. A maioria dos alunos falava ao mesmo tempo, outros só sabiam se expressar gritando e não paravam no lugar. Também existia um grau de agressividade entre os alunos na própria sala de aula.

Após um mês do início da observação, a professora concluiu que trabalhar em equipe poderia diminuir a indisciplina, problema recorrente na classe. Ela formou equipes de no máximo seis crianças e escolheu um líder para cada grupo, o qual ficaria encarregado de cobrar as atividades que a professora pediria, assim como cobrar o silêncio do grupo e a ajuda dos colegas entre si.

Esta estratégia da professora melhorou parcialmente o comportamento de alguns alunos. Em alguns grupos, os alunos líderes conseguiram conquistar a atenção e o silêncio da equipe; em outros, nem deram importância para o líder e alguns representantes não assumiram a tarefa de líder. Nestas equipes, a bagunça aumentou.

Os alunos que no primeiro semestre apresentavam maiores dificuldades e estavam mais desmotivados haviam mudado de atitude e se encontravam mais alegres e felizes, pois já conseguiam realizar as atividades propostas pela professora.

Em contraposição, os alunos da escola particular eram totalmente cobrados com relação à disciplina, pois é um colégio religioso cujo objetivo é formar personalidades autênticas, livres, formação feminina.

Durante as observações em sala, notou-se que o colégio se adapta à modernidade, sem renunciar aos seus princípios. A professora regente só começa 
a aula após total silêncio da sala. Enquanto houver barulho em sala, a professora cruza os braços e espera que todas as alunas se acalmem e fiquem quietas. Após conseguir o silêncio e a atenção da turma, a professora realiza uma oração com as alunas e somente depois inicia a aula.

A metodologia utilizada pela professora está de acordo com a escola tradicional. A professora utilizou com muita freqüência os cadernos, os livros didáticos e diversas atividades em folha de sulfite.,sendo a maioria delas executadas em sala de aula. $\mathrm{Na}$ instituição, havia inúmeras atividades paralelas às atividades da sala de aula: aulas de inglês, educação física, música, religião e artes. O ensino religioso católico é muito forte na educação das alunas.

Durante a observação em sala de aula realizada no primeiro e no segundo semestre em cada uma das escolas, aplicamos uma atividade para verificar o nível de escrita em que as crianças se encontravam. Estes exercícios foram aplicados no final de cada semestre, mediante a autorização prévia das professoras regentes das turmas. Nossa intenção foi apenas identificar o nível de alfabetização dos alunos das duas escolas, no início e no final deste trabalho.

Os desenhos foram cópias xérox em que as crianças pintaram e fizeram frases sobre o tema proposto na atividade. Os exemplos a seguir mostram os níveis encontrados em cada uma das escolas.

As figuras de 1 e 2 indicam os modelos elaborados pelos alunos da escola municipal no $1^{\circ} \mathrm{e} 2^{\circ}$ semestre.

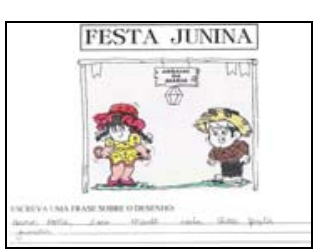

Figura 1. Análise da escrita.

$1^{\circ}$ Semestre

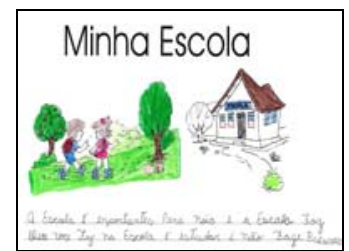

Figura 2. Análise da escrita $2^{\circ}$ Semestre
Os exercícios dos alunos da instituição particular estão representados nas figuras 3 e 4 abaixo, relativos ao $1^{\circ} \mathrm{e}$ $2^{\circ}$ semestre, respectivamente.

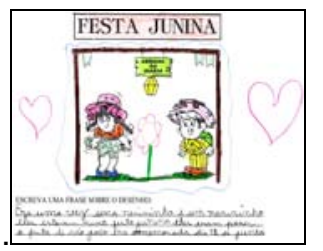

Figura 3. Análise da escrita $1^{\circ}$ semestre

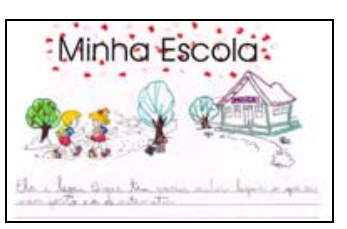

Figura 4. Análise da escrita$2^{\circ}$ semestre
Quanto às entrevistas, visando a compreensão de como as professoras vivem as situações em sala de aula, 
apresentou-se uma questão aberta, nãodiretiva, para que as elas falassem à vontade sobre $\mathrm{o}$ assunto solicitado. Concluída esta etapa, foram apresentadas mais algumas perguntas para o melhor esclarecimento do objeto de pesquisa do trabalho.

As entrevistas foram gravadas sem tempo limitado para as respostas, respeitando-se assim o vocabulário, o estilo das respostas, da fala e as eventuais contradições. Todas as entrevistas foram transcritas na íntegra e constituíram um dos focos de análise do trabalho.

A Tabela 1 abaixo demonstra 0 resumo das entrevistas.

Tabela 1 - Resumo das Entrevistas com as professoras das escolas particular e municipal

\begin{tabular}{|c|c|c|c|c|c|c|}
\hline & Perguntas & $\begin{array}{l}\text { Professor } \\
1\end{array}$ & $\begin{array}{l}\text { Professo } \\
\text { r } 2\end{array}$ & $\begin{array}{l}\text { Profes } \\
\text { sor } 3 \\
\end{array}$ & $\begin{array}{l}\text { Profess } \\
\text { or } 4\end{array}$ & $\begin{array}{l}\text { Professor } \\
5\end{array}$ \\
\hline 1 & $\begin{array}{l}\text { Formação } \\
\text { e tempo de } \\
\text { formação }\end{array}$ & $\begin{array}{l}\text { Pedagogia } \\
\text { e } \\
\text { especializ } \\
\text { ação em } \\
\text { psicopeda } \\
\text { gogia;15 } \\
\text { anos }\end{array}$ & $\begin{array}{l}\text { Magistér } \\
\text { io e } \\
\text { História; } \\
3 \text { anos }\end{array}$ & $\begin{array}{l}\text { Magist } \\
\text { ério e } \\
\text { Pedago } \\
\text { gia; 25 } \\
\text { anos }\end{array}$ & $\begin{array}{l}\text { Pedago } \\
\text { gia; } 2 \\
\text { anos }\end{array}$ & $\begin{array}{l}\text { Magistéri } \\
\text { o e } \\
\text { Letras; } \\
10 \text { anos }\end{array}$ \\
\hline 2 & $\begin{array}{l}\text { Metodolog } \\
\text { ia em sala } \\
\text { de aula }\end{array}$ & $\begin{array}{l}\text { Misto - } \\
\text { tradicional } \\
\text { construtivi } \\
\text { smo e } \\
\text { GEEMPA }\end{array}$ & $\begin{array}{l}\text { Misto - } \\
\text { tradicion } \\
\text { al, } \\
\text { construti } \\
\text { vismo e } \\
\text { GEEMP } \\
\text { A }\end{array}$ & $\begin{array}{l}\text { Eclétic } \\
\text { o }\end{array}$ & $\begin{array}{l}\text { Constru } \\
\text { tivismo }\end{array}$ & $\begin{array}{l}\text { Tradicion } \\
\text { al e } \\
\text { Construti } \\
\text { vismo }\end{array}$ \\
\hline 3 & $\begin{array}{l}\text { Ligação } \\
\text { entre } \\
\text { metodologi } \\
\text { a e } \\
\text { conteúdo }\end{array}$ & $\begin{array}{l}\text { Atividade } \\
\text { s com } \\
\text { música }\end{array}$ & $\begin{array}{l}\text { A partir } \\
\text { de uma } \\
\text { história } \\
\text { contada }\end{array}$ & $\begin{array}{l}\text { A } \\
\text { partir } \\
\text { do } \\
\text { texto } \\
\text { aplicad } \\
\text { o }\end{array}$ & $\begin{array}{l}\text { A partir } \\
\text { de } \\
\text { história } \\
\mathrm{s} \text { e } \\
\text { palavras } \\
\text { chaves }\end{array}$ & $\begin{array}{l}\text { De } \\
\text { maneira } \\
\text { interdisci } \\
\text { plinar }\end{array}$ \\
\hline 4 & $\begin{array}{l}\text { Recursos/ } \\
\text { Material } \\
\text { em sala de } \\
\text { aula }\end{array}$ & $\begin{array}{l}\text { Folha } \\
\text { mimeogra } \\
\text { fada; } \\
\text { caderno } \\
\text { de } \\
\text { desenho e } \\
\text { histórias }\end{array}$ & $\begin{array}{l}\text { Vídeo, } \\
\text { sulfite, } \\
\text { quadro e } \\
\text { rádio }\end{array}$ & $\begin{array}{l}\text { Sucata } \\
\text { s e } \\
\text { embala } \\
\text { gens }\end{array}$ & $\begin{array}{l}\text { Massa } \\
\text { de } \\
\text { modelar } \\
\text {, sulfite, } \\
\text { cartolin } \\
\text { a }\end{array}$ & $\begin{array}{l}\text { Materiais } \\
\text { diversos, } \\
\text { sempre } \\
\text { disponíve } \\
\text { is }\end{array}$ \\
\hline 5 & $\begin{array}{l}\text { Conhecime } \\
\text { nto do PPP } \\
\text { da escola }\end{array}$ & $\begin{array}{l}\text { Conhece e } \\
\text { já } \\
\text { trabalhou } \\
\text { os } \\
\text { conteúdos }\end{array}$ & $\begin{array}{l}\text { Conhece } \\
\text { algumas } \\
\text { partes } \\
\text { gerais }\end{array}$ & $\begin{array}{l}\text { Conhe } \\
\text { ce e } \\
\text { ajudou } \\
\text { a fazer }\end{array}$ & $\begin{array}{l}\text { Já leu, } \\
\text { mas } \\
\text { conside } \\
\text { ra uma } \\
\text { utopia }\end{array}$ & $\begin{array}{l}\text { Conhece, } \\
\text { mas não } \\
\text { lembra } \\
\text { do } \\
\text { conteúdo }\end{array}$ \\
\hline 6 & $\begin{array}{l}\text { Atividades } \\
\text { extraclasse }\end{array}$ & $\begin{array}{l}\text { Não } \\
\text { realizou }\end{array}$ & $\begin{array}{l}\text { Fez } \\
\text { geladinh } \\
\text { o, } \\
\text { gelatina, } \\
\text { suspiro e } \\
\text { sanduích } \\
\text { e }\end{array}$ & $\begin{array}{l}\text { Aulas } \\
\text { no } \\
\text { pátio } \\
\text { da } \\
\text { escola }\end{array}$ & $\begin{array}{l}\text { Não } \\
\text { houve } \\
\text { por falta } \\
\text { de } \\
\text { recursos }\end{array}$ & $\begin{array}{l}\text { Pouco } \\
\text { freqüente }\end{array}$ \\
\hline 7 & Avaliações & Contínua & No & Diárias & Diária & Prova \\
\hline
\end{tabular}

\begin{tabular}{|c|c|c|c|c|c|c|}
\hline & & $\begin{array}{l}\text { e sem } \\
\text { provas } \\
\text { escritas }\end{array}$ & $\begin{array}{l}\text { início e } \\
\text { no final } \\
\text { do } \\
\text { bimestre }\end{array}$ & & & $\begin{array}{l}\text { folha de } \\
\text { atividade } \\
\text { s }\end{array}$ \\
\hline 8 & $\begin{array}{l}\text { Reforço } \\
\text { estudantil }\end{array}$ & $\begin{array}{l}\text { Existe } \\
\text { uma vez } \\
\text { por } \\
\text { semana }\end{array}$ & $\begin{array}{l}\text { Existe } \\
\text { uma vez } \\
\text { por } \\
\text { semana }\end{array}$ & $\begin{array}{l}\text { Existe } \\
\text { uma } \\
\text { vez } \\
\text { por } \\
\text { seman } \\
\text { a }\end{array}$ & $\begin{array}{l}\text { Existe } \\
\text { uma vez } \\
\text { por } \\
\text { semana }\end{array}$ & $\begin{array}{l}\text { Existe em } \\
\text { período } \\
\text { contrário }\end{array}$ \\
\hline 9 & $\begin{array}{l}\text { Percepção } \\
\text { do } \\
\text { aprendizad } \\
\text { o dos } \\
\text { alunos }\end{array}$ & $\begin{array}{l}\text { Quando } \\
\text { estão } \\
\text { lendo e } \\
\text { escrevend } \\
\text { o }\end{array}$ & $\begin{array}{l}\text { Quando } \\
\text { estão } \\
\text { lendo e } \\
\text { escreven } \\
\text { do }\end{array}$ & $\begin{array}{l}\text { Quand } \\
\text { o } \\
\text { demon } \\
\text { stram } \\
\text { que } \\
\text { aprend } \\
\text { eram o } \\
\text { som } \\
\text { das } \\
\text { letras }\end{array}$ & $\begin{array}{l}\text { Quando } \\
\text { o aluno } \\
\text { está } \\
\text { lendo }\end{array}$ & $\begin{array}{l}\text { Quando } \\
\text { estão } \\
\text { lendo e } \\
\text { escreven } \\
\text { do }\end{array}$ \\
\hline $\begin{array}{l}1 \\
0\end{array}$ & $\begin{array}{l}\text { Existência } \\
\text { de elo } \\
\text { entre } \\
\text { família e } \\
\text { escola }\end{array}$ & $\begin{array}{l}\text { Difícil e } \\
\text { apenas } \\
\text { com uma } \\
\text { minoria } \\
\text { dos alunos }\end{array}$ & $\begin{array}{l}\text { Muito } \\
\text { relativo, } \\
\text { pois } \\
\text { pode ser } \\
\text { prejudici } \\
\text { al }\end{array}$ & $\begin{array}{l}\text { Muito } \\
\text { pouco }\end{array}$ & $\begin{array}{l}\text { Não há } \\
\text { muito }\end{array}$ & $\begin{array}{l}\text { Muito } \\
\text { grande }\end{array}$ \\
\hline $\begin{array}{l}1 \\
1\end{array}$ & $\begin{array}{l}\text { Maior } \\
\text { problema } \\
\text { enfrentado }\end{array}$ & $\begin{array}{l}\text { Quando a } \\
\text { criança é } \\
\text { revoltada }\end{array}$ & $\begin{array}{l}\text { Aluno } \\
\text { de } 9 \\
\text { anos } \\
\text { cujos } \\
\text { pais } \\
\text { eram } \\
\text { usuários } \\
\text { de } \\
\text { drogas } \\
\end{array}$ & $\begin{array}{l}\text { Aluno } \\
\text { de } 13 \\
\text { anos } \\
\text { na } \\
\text { primeir } \\
\text { a série }\end{array}$ & $\begin{array}{l}\text { Criança } \\
\mathrm{s} \quad \text { com } \\
\text { desestru } \\
\text { tura } \\
\text { familiar }\end{array}$ & $\begin{array}{l}\text { Gêmeas } \\
\text { com } \\
\text { problema } \\
\mathrm{s} \\
\text { familiare } \\
\mathrm{s} \quad \text { que } \\
\text { reprovara } \\
\mathrm{m}\end{array}$ \\
\hline $\begin{array}{l}1 \\
2\end{array}$ & $\begin{array}{l}\text { O que mais } \\
\text { encanta na } \\
\text { alfabetizaç } \\
\text { ão }\end{array}$ & $\begin{array}{l}\text { Quando a } \\
\text { criança } \\
\text { começa a } \\
\text { ler }\end{array}$ & $\begin{array}{l}\text { Quando } \\
\text { descobre } \\
\mathrm{m} \quad \mathrm{a} \\
\text { leitura } \\
\text { rapidam } \\
\text { ente }\end{array}$ & $\begin{array}{l}\text { Quand } \\
\text { o estão } \\
\text { lendo }\end{array}$ & $\begin{array}{l}\text { Evoluçã } \\
\text { o de } \\
\text { cada } \\
\text { criança }\end{array}$ & $\begin{array}{l}\text { Ver todos } \\
\text { lendo e } \\
\text { escreven } \\
\text { do, } \\
\text { principal } \\
\text { mente os } \\
\text { alunos } \\
\text { que } \\
\text { apresenta } \\
\text { ram } \\
\text { dificulda } \\
\text { des }\end{array}$ \\
\hline
\end{tabular}

\section{Conclusão}

Quanto à observação em sala, houve pontos positivos e negativos, pois esta nem sempre é vista com bons olhos, seja pela escola,seja pelo professor regente.

As entrevistas com as professoras, num primeiro momento, foram vistas com resistência por parte das mesmas, pois não se sentiram à vontade sabendo que a entrevista seria gravada. Informamos que os nomes das escolas, dos professores e dos alunos não seriam divulgados por questões éticas.
Existe
o
Projeto
Político

Pedagógico nas escolas. Os professores 
da escola pública têm mais acesso ao PPP do que os professores da escola particular, inclusive com a participação ativa na elaboração deste documento. Podemos perceber que alguns professores da escola pública participaram do processo de elaboração do PPP da escola.

Já em sala de aula, a teoria contida no projeto não é exercida, pois existe uma defasagem do conhecimento das teorias e metodologias que dão embasamento à alfabetização. Percebe-se que a maioria dos professores ainda adota um ecletismo, muitas vezes devido à grande autonomia que $o$ professor possui em sala, sem supervisão e cobrança.

$\mathrm{Na}$ escola particular esta hipótese é evidente, primeiramente pelo fato da excelente estruturação e fundamentação metodológica que o PPP apresenta. Em segundo lugar porque o professor sabe como a escola pensa e adota o mesmo tipo de postura de pensamento em sala de aula. Neste sentido, a educação proposta pela escola está coerente com a metodologia observada em sala de aula. É claro que mesmo o professor citando um ecletismo metodológico, esta combinação acaba não existindo na escola particular. A metodologia adotada em sala de aula fica totalmente fundamentada na escola tradicional.

$\mathrm{Na}$ escola pública, já existe o problema da falta de fundamentação do PPP. Entretanto, mesmo sendo a metodologia de ensino citada de forma superficial, fica clara a opção da escola pelo construtivismo de Piaget e Vygostky. Já na prática, o que foi observado em sala de aula foi um ecletismo de teorias, não se restringindo apenas ao construtivismo de Piaget e Vygostky, mas também a outras bases de ação metodológicas, como é o caso do GEEMPA

Este estudo foi muito importante em nossa formação como professora do ensino fundamental, visto que possibilitou um aprofundamento teórico das práticas pedagógicas utilizadas na alfabetização.

A oportunidade de vivenciar um estudo sobre teoria e prática na rotina de cada escola permitiu-nos um crescimento significativo como professora alfabetizadora, principalmente porque deixamos o contexto de ser agente da alfabetização para ser uma observadora deste processo. Foi muito rico poder realizar este estudo em duas escolas tão distintas, tanto na sua estrutura $e$ localização, quanto no seu contexto social e cultural, mas ambas com o mesmo objetivo, o de alfabetizar seus alunos na primeira série do ensino fundamental.

Uma grande questão levantada durante este estudo está no fato da ausência de comprometimento com o PPP da escola, pois, além de ser uma exigência de leis governamentais, é um instrumento para o amadurecimento da escola como um todo. Por isso, cabe à escola, representada por sua direção pedagógica, por seus professores, por pais e alunos, criarem o comprometimento que o PPP exige. Isto só pode ser alcançado, primeiramente, a partir do conhecimento do significado e da importância do PPP, em segundo lugar, através da divulgação do processo que o PPP exige e, por último, 
mas não menos importante, através do comprometimento de todos com a escola, ou seja, com a educação de nossos filhos.

\section{REFERÊNCIAS BIBLIOGRÁFICAS}

ARCE, Alessandra. O construtivismo. In: DUARTE, Newton (org). Sobre o Construtivismo: polêmicas do nosso tempo. Campinas: Autores Associados, 2000.

BARRETO, Vera. Paulo Freire para educadores. 6.ed. São Paulo: Arte e Ciência, 2004.

BECKER, Fernando. Pensando a construção do conhecimento. In: MORAES, Vera Regina Pires (org). Melhoria do Ensino e Capacitação Docente. Porto Alegre, Ed. Da Universidade, 1996.

BERTAN, Levino. Aspectos da trajetória do ideal de liberdade na educação brasileira 1930-1990. 1994. 121f. Dissertação (Doutorado em Filosofia e História da Educação) - Faculdade de Educação, Universidade Estadual de Campinas, Campinas, SP.

CARVALHO, Marlene. Alfabetizar e letrar: um diálogo entre a teoria e a prática. Petrópolis: Vozes, 2005.

LIMA, Maria Aparecida. O Projeto Político Pedagógico na percepção dos profissionais que atuam na escola. Anais do VI Encontro de Pesquisa e Educação da Região Sudeste, 2004, Rio de Janeiro,
Universidade do Estado do Rio de Janeiro, 2004. p. 187.

MOLL, Jaqueline. Alfabetização possível: reinventando o ensinar e o aprender. Porto Alegre: Mediação, 1996.

MORAIS, Regis de. Estudo de filosofia da cultura. São Paulo: Loyola, 1992.

NOGARO, Arnaldo. Reflexões sobre pressupostos que norteiam $\mathrm{o}$ projeto político pedagógico da escola. Perpectiva. Erechin, RS, vol.19, n.67, p.67-74, set. 1995.

PROJETO político pedagógico escola municipal TCB, 2002, $37 f$.

PROJETO político pedagógico escola particular CMD, vol. I, 2001, 439f.

PROJETO político pedagógico escola particular CMD, vol. II, 2001, 469f.

REGO, Teresa Cristina. Vygotsky: uma perspectiva histórico-cultural da educação. 3.ed. Petrópolis: Vozes, 1995.

ROCHA, Ana Luiza C da. Alfabetização em três meses de jovens e adultos Piauí 2003.

SEVERINO, Antônio Joaquim. Filosofia da Educação: construindo a cidadania. São Paulo. F.T.D., 2000. 